\section{Routine tests reveal unknown strains of BSE prions}

Marika Willerroider, Munich

New strains of the prion that causes bovine spongiform encephalopathy (BSE) have been reported by scientists in Italy and Japan.

Until now, all known cases of BSE have been caused by the same prion strain. But experts have long suspected that additional strains of BSE might be lurking in cattle, which they fear could propagate new human diseases, as happened in the 1990s outbreak of variant Creutzfeldt-Jakob disease.

The new strains are readily detected by existing tests for BSE. The researchers identified them from brain samples using a technique called the western blot, which produces a series of bands that represent the prions present. In the case of the new strains, the western blot showed a different pattern of bands from conventional BSE. Researchers remain concerned that if prion variants continue to emerge, some of them may escape detection by existing tests.

On 6 October, Morikazu Shinagawa of the National Institute of Animal Health in Tsukuba, Japan, reported that a bullock born there had tested positive for BSE, and that the characteristics of the prion were different from those of classical BSE. Two days later, Maria Caramelli at the National Reference Centre for Animal Encephalopathies in Turin, Italy, reported that two of 110 cows that had tested positive for BSE involved similarly distinctive prions.

In both cases, the prions were found during abattoir sampling of symptomfree animals. The Japanese and Italian scientists have yet to confirm whether the two strains are identical.

"What we have is definitively a new variant, but it was detectable by a conventional rapid test, so there is no immediate risk of a new epidemic," says Caramelli, who presented her work at the International Prion Conference in Munich last week.

"There has never been good reason to believe that there should only be one variant in cattle," says Adriano Aguzzi, a prion expert at the University Hospital in Zürich, who points out that several strains of spongiform encephalopathy have been found in sheep and in humans. "It will be interesting to find out if the new prion variants were introduced in cattle feed, or if they spontaneously emerged in the cattle as a result of a gene mutation," he adds.

\title{
Physician launches public protest over medical Nobel
}

Helen Pearson

It should have been a time of celebration, but instead the Nobel prizes were last week caught up in a very public row. Angered by his exclusion from this year's medicine award, a New York-based inventor took out adverts in US newspapers calling for a share of the prize.

On 6 October, physicists Paul Lauterbur of the University of Illinois, UrbanaChampaign, and Peter Mansfield of the University of Nottingham, UK, won the Nobel Prize in Physiology or Medicine for their role in developing magnetic resonance imaging (MRI) as a medical technique for scanning the human body (see Nature 425, 547; 2003).

But the announcement triggered a hostile reaction from Raymond Damadian, a physician who claims to have invented the technique. He protested by placing full-page advertisements in last week's The Washington Post, The New York Times and Los Angeles Times. "If I had never been born, there would never be MRI today," he told Nature.

Damadian's advertisements ask readers to cut out a coupon and send it to the Nobel committee demanding that he be recognized as the joint third winner of the prize - a forlorn hope, as Nobel committees never discuss the justification of their awards. Damadian says that he has not yet totted up the full cost of the adverts, which were paid for by his MRI imaging company FONAR in Melville, New York, but a news report in The Washington Post valued the slot in that newspaper alone at about $\$ 80,000$.

Damadian says that he originally came up with the idea of using the then-established physical scientists' technique of nuclear magnetic resonance (NMR) to distinguish between states of body tissue, an approach that became known as MRI. In 1971, he published a paper in Science showing that cancerous and healthy tissue can be told apart by the different NMR signals that they emit (R. Damadian Science 171, 1151-1153; 1971). He later patented a technique to scan the body for tumours by taking a series of NMR readings from different spots.

MRI experts agree that Damadian's concept was important, but say that without Lauterbur and Mansfield's contributions the MRI technique would not be where it is today. The pair showed how to use a graded magnetic field, which varies from strong to weak across an object, to rapidly take its image. "The real breakthroughs came from Lauterbur and Mansfield," says Richard Ernst, of the Swiss Federal Institute of Technology, Zurich, who won the 1991 chemistry Nobel for improving the resolution of NMR.

Researchers add that concerns about Damadian's response - which they say was anticipated before the announcement have held up the award of a Nobel prize for MRI. The Nobel committee, Mansfield and Lauterbur all declined to comment.

Disputes within the scientific community often dog the Nobels, but observers say that this latest protest in the wider media breaks new ground. "It's absolutely sensational. I've never heard of anything like that," says Tore Frängsmyr of Uppsala University in Sweden, who edits the Nobel Foundation yearbook.

Frängsmyr and others predict that publicized scuffles over the Nobels might become more common in the future, partly because today's top scientists increasingly hold celebrity status. Bruised egos are particularly likely in medicine, where discoveries are often made by large collaborative groups the rules state that Nobel prizes can be awarded to no more than three individuals (see Nature 413, 560-564; 2001).

Whatever the outcome of Damadian's complaint, observers say that such arguments could diminish the esteem in which the Nobel prizes are held. The prize-giving ritual could come to eclipse the underlying achievement, warns science historian Robert Marc Friedman of the University of Oslo, Norway. "It would be good if there was a lot less hysteria around the prize," he says. 